\title{
Development of waterjet-assisted cassava peeler
}

\author{
Raymond G. Sumaria ${ }^{1}$ and Daniel Leslie S. Tan ${ }^{2 *}$
}

\begin{abstract}
The study aimed to develop a water jet-assisted cassava peeler and evaluate its technical performance in terms of peeling capacity, peeling efficiency, and tuber loss during peeling. Performance evaluation of the developed peeler included treatments which were the combinations of the three methods of peeling (use of circular nozzle, use of flat nozzle, and the manual peeling using a knife) and three diameter ranges of cassava roots $(35 \pm 5 \mathrm{~mm} ; 45 \pm 5 \mathrm{~mm} ; 55 \pm 5 \mathrm{~mm})$. Results showed that the peeling capacity of the water jet-assisted peeler with circular nozzle was significantly higher than manual peeling but not significantly different to the water jet-assisted peeler with flat nozzle. The diameter of cassava roots used also significantly affected the peeling capacity of the different peeling methods; lower capacity for smaller diameter cassava roots and higher capacity for bigger diameter cassava roots.
\end{abstract}

Keywords: cassava peeling, peeler, water jet

\section{INTRODUCTION}

Cassava (Manihot esculenta Crantz) is considered one of the most important food crops in the tropical areas including Asia, Africa and Latin America. The tuberous roots are rich in carbohydrates, which can constitute up to $35 \%$ of the total root weight on a wet basis (Onwueme 1978). In 2009, 242 million tonnes have been harvested (FAO 2009). The review conducted jointly by IITA and FUTA in 2005 revealed that cassava peeling is still largely done manually. Tan et al (1996) reported that in the village level processing of cassava flour in the Philippines, the manual cassava peeling operation contributes about $50 \%$ of the total labor cost.

There are several methods of peeling cassava, which include manual, chemical, steaming and mechanical methods. Each has its own advantages and disadvantages (Hassan 2012). In manual method, a knife is used to manually remove the peel. It is the most common method of peeling cassava roots tuber

\footnotetext{
'Department of Agricultural Engineering, Visayas State University, Baybay City, Leyte, Philippines

${ }^{2}$ Philippine Root Crop Training Center (PhilRootcrops), Visayas State University, Baybay City, Leyte 6521 Philippines

* Corresponding Author. Address: Philippine Root Crop Training Center (PhilRootcrops), Visayas State University, Baybay City, Leyte 6521 Philippines; Email: danielleslie.tan@vsu.edu.ph DOI: 10.32945/atr40210.2018
} 
today. However, this method is tedious, labor consuming and still wasteful in terms of flesh loss. The chemical method involves chemical actions and thermal shock, which leads to softening and loosening of the skin using caustic soda $(\mathrm{NaOH})$. The disadvantages of this method of peeling cassava, among others, include difficulty in controlling the penetration of chemical into the cassava tuber, and the difficulty in the removal of chemical traces as it may be poisonous. In steaming method, the tubers are subjected to high steam pressure over a short period of time to avoid partial cooking (or eventual cooking). The disadvantage is that the tubers could be subjected beyond the time required, which will lead to cooking.

Adetan et al (2003) designed a spring-loaded cassava peeling machine with five spring-loading points resulting in $15 \%$ broken tubers and peeling efficiency of $98.8 \%$. Many other mechanisms have been devised for the mechanical peeling of cassava. These mechanisms include also the continuous process, abrasive belt conveyors and batch abrasion types among others. These methods of peeling have not yielded the desired results, hence the continued research in this area. An extensive literature research was conducted to determine the state of the art in cassava processing to solve the problem of cassava peeling and to serve as a base for the commercial production and utilization of cassava peeling machines (Hillocks 2002, Kawano 2000). From these literature, no attempt has been made to use the water jet in the peeling of cassava tubers, hence this study. This study aimed to develop a water jet-assisted cassava peeler and compare this to manual peeling.

\section{MATERIALS AND METHODS}

\section{Design Consideration}

The following considerations were applied in developing the water jet-assisted cassava peeler: 1) high peeling capacity, 2) high peeling efficiency, 3) low tuber loss, and 4 ) reduce the number of cassava processing operations.

\section{Fabrication of the Water Jet-Assisted Cassava Peeler}

The machine was fabricated based from the working drawings shown in Figures 1. It was fabricated at the Philrootcrops Processing Laboratory, Visayas State University, Baybay City, Leyte.

\section{Evaluation of Water Jet-Assisted Cassava Peeler}

The technical performance of the water jet-assisted cassava peeler was evaluated in terms of peeling capacity, peeling efficiency, and percent tuber loss.

\section{Peeling Mechanism}

Figure 2 shows the schematic diagram of the cassava peeling mechanism that was applied in the development of the water jet-assisted peeler for cassava. It consisted of a blade welded parallel to the top side and extended at the front end of the nozzle.

The peeling process is initiated by slitting the peels of the cassava root. When 
through the $12.7 \mathrm{~mm}(1 / 2 \mathrm{in}$.) diameter pipe and through the $2 \mathrm{~mm}$ diameter nozzle. At the nozzle opening, the water velocity increases due to sudden reduction of the flow diameter (nozzle opening), and so generating the water jet. As the blade cuts through the peels, the water jet exerts considerable pressure between the peels and the flesh of the cassava roots and so facilitates the peeling process.

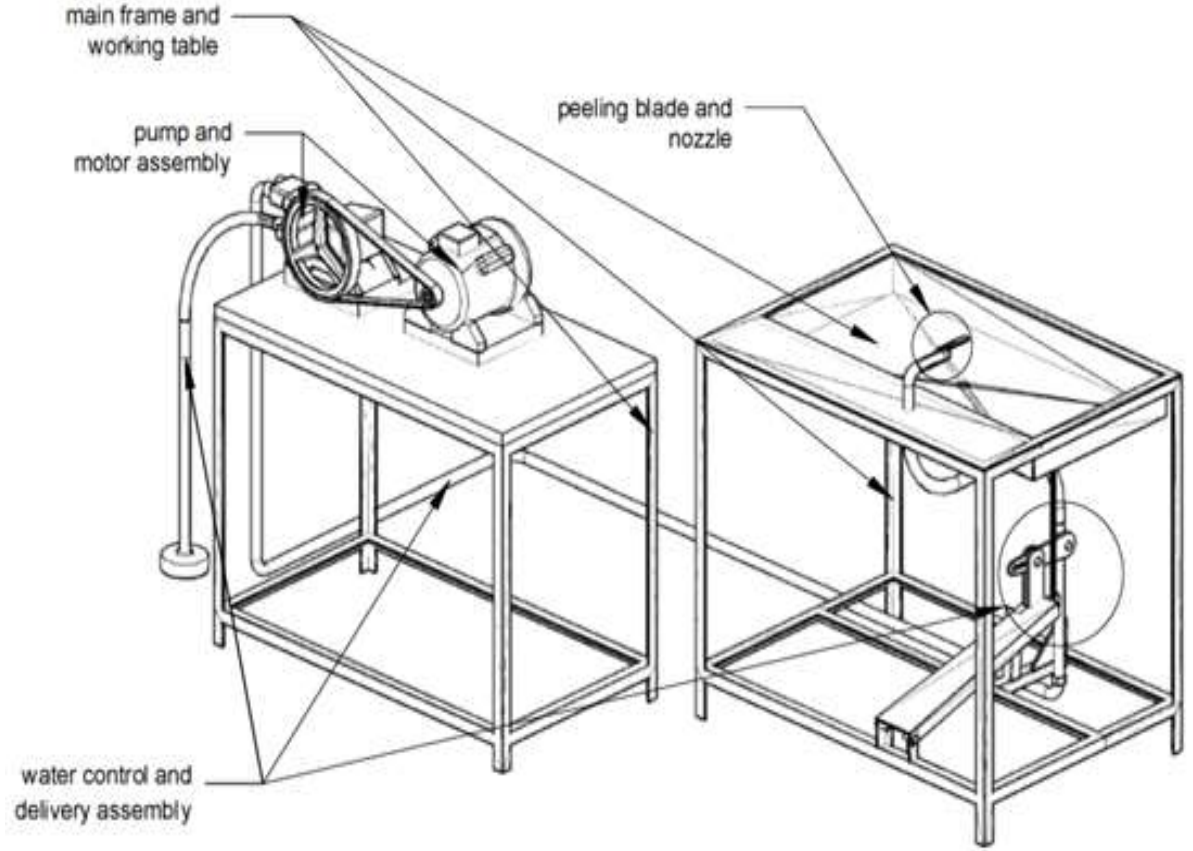

Figure 1. Isometric view of the water-jet assisted cassava peeler

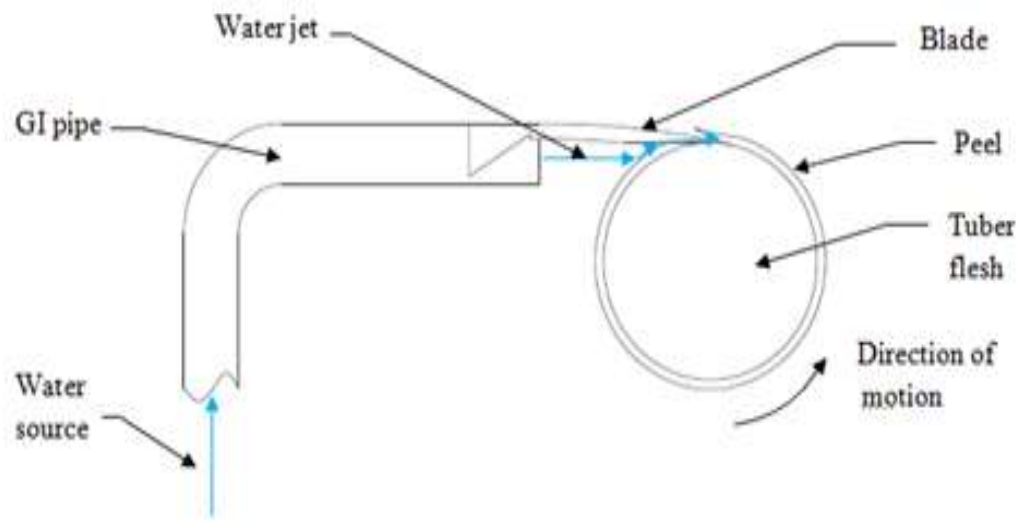

Figure 2. Schematic diagram of the cassava peeling mechanism 
Development of waterjet-assisted cassava peeler

\section{Tuber Preparation}

The Lakan cassava variety, harvested from the PhilRootcrops experimental field was used in the experiment. The roots were cut into $100 \mathrm{~mm}$ length and sorted to three diameter ranges ( $35 \pm 5 \mathrm{~mm} ; 45 \pm 5 \mathrm{~mm}$; and $55 \pm 5 \mathrm{~mm}$ ). The amount of cut roots used in every trial was $5 \mathrm{~kg}$.

\section{The Peeling Operation Using the Water Jet-Assisted Peeler}

The gage pressure of the water jet was $30 \mathrm{~kg} / \mathrm{cm}^{2}$ when the control valve was closed and $10 \mathrm{~kg} / \mathrm{cm}^{2}$ when the valve was opened. Each of the cassava roots was peeled by holding the unpeeled root with one hand, and with the other hand holding the water jet-assisted peeler, the blade of the peeler is forced through the peel through the slit made initially to the roots. After the blade penetrates through the peel, the control valve is opened by means of the pedal for the water to flow through the nozzle then to the peels at high pressure, thereby facilitating the peeling process. The time duration after peeling the $5 \mathrm{~kg}$ cassava tuber was then recorded and the peeling capacity was computed.

\section{Experimental Design and Treatment}

The experiments were conducted using Randomized Complete Block Design (RCBD) in $3 \times 3$ factorial (three different peelers in combination with the three different sizes of cassava roots) in three replications. The three peelers were the two water jet-assisted peelers (flat and circular nozzle openings) and a manual peeler (knife).

\section{Water Jet Nozzle Design}

The nozzle in Figure 3(a) has a circular opening having a diameter of approximately $2 \mathrm{~mm}$ and the nozzle in Figure $3(\mathrm{~b})$ has a nozzle that was flattened so that the cross-section is in rectangular form having a dimension of approximately $1 \mathrm{~mm} \times 10 \mathrm{~mm}$. The flat rectangular nozzle was formed so that the form of the flow of water towards the tuber is parallel to the horizontal blade position.

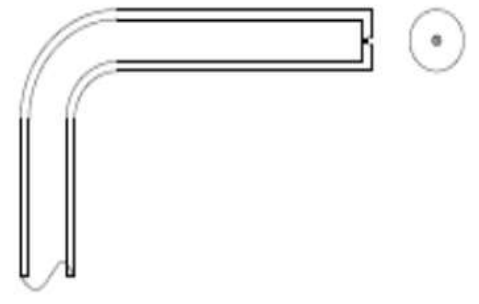

(a) Circular nozzle

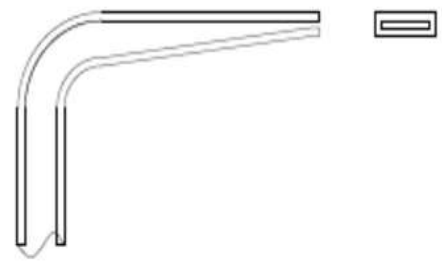

(b) Flat nozzle

Figure 3. Two designed nozzle openings (a) cicular and (b) flat nozzle 


\section{Diameter of the Cassava Root}

The following ranges of cassava root diameter were used in the experiment.

$$
\begin{aligned}
& D_{1}=35 \mathrm{~mm} \pm 5 \mathrm{~mm} \\
& D_{2}=45 \mathrm{~mm} \pm 5 \mathrm{~mm} \\
& D_{3}=55 \mathrm{~mm} \pm 5 \mathrm{~mm}
\end{aligned}
$$

\section{The Peeling Process Flow}

Figure 4 shows the peeling process flow of cassava roots. The cassava roots were manually sorted according to their respective sizes $(35 \pm 5 \mathrm{~mm} ; 45 \pm 5 \mathrm{~mm}$; and $55 \pm 5 \mathrm{~mm}$ ). The cassava roots were cut into $100-\mathrm{mm}$ length and peeled manually, and with the water jet-assisted peeler with the two nozzle designs.

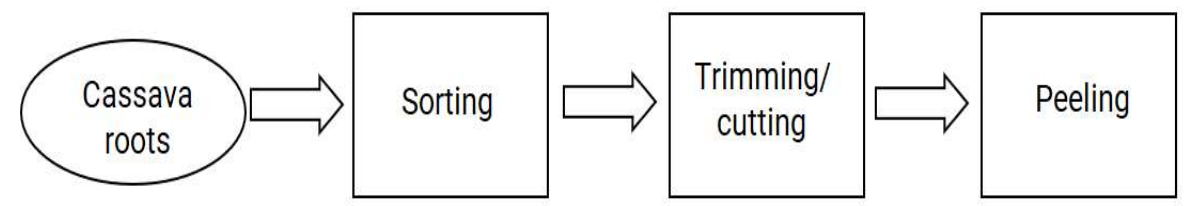

Figure 4. Cassava peeling process flow

\section{Data gathered and Parameters Evaluated}

The peeling efficiency, percentage flesh tuber loss, and peeling capacity of peelers using cassava roots were determined. To determine the percentage by weight of peel for the respective sizes and compared this to the water jet-assisted peelers, manual peeling of the cassava roots using a knife was also done and the amount of peels recovered were recorded.

The following formulas were used.

Percent weight of peel (\%)

$$
\% \text { weight of peels }=\frac{W_{p 1}}{W_{i}} \times 100
$$

Peeling efficiency (P.E, \%)

$$
\text { P.E. }=\frac{W_{R}}{W_{P}} \times 100
$$


Development of waterjet-assisted cassava peeler

Percent flesh tuber loss (P.E., \%)

$$
\text { P.E. }=\frac{\mathrm{W}_{\mathrm{R}}}{\mathrm{W}_{\mathrm{T}}} \times 100
$$

Peeling capacity $\left(\mathrm{C}_{\mathrm{p}}\right)$

$$
C_{p}=\frac{W_{i}}{t_{P}}
$$

Where:

$$
\begin{array}{ll}
W_{i} & =\text { weight of unpeeled tubers } \\
W_{p} & =\text { weight of peels by manual peeling } \\
W_{T P} & =\text { total weight of peels } \\
W_{R} & =\text { weight of flesh removed by water-jet assisted peelers } \\
W_{T} & =\text { total weight of tuber } \\
t_{p} & =\text { time taken for the tuber in peeling (manual and } \\
& \text { mechanical) }
\end{array}
$$

\section{Analysis of Data}

The performance of the three peelers at different parameters of peeling was compared using the Randomized Complete Block Design (RCBD) following the analysis of variance (ANOVA) table. Further test for significance of treatments means was done using Tukey's Honest Significant Difference Test.

\section{RESULTS AND DISCUSSION}

\section{Description of the Water Jet-Assisted Peeling Machine}

The main parts of the cassava peeler as shown in Figure 5 were: (1) water pump and motor assembly, (2) peeling blade and nozzle assembly, (3) frame and table, and (4) water control and delivery assembly.

\section{The water pump and motor assembly}

A 1-hp motor water pump (K.K.KAWASAKI: FN-22C) delivered the water at high pressure from the water container to the nozzle outlet.

\section{The peeling blade and nozzle assembly}

The blade was made out of $70 \mathrm{~mm} \times 15 \mathrm{~mm} \times 2 \mathrm{~mm}$ stainless steel which is sharpened at one end used to slit open the cassava peel and where the water jet is also directed. The blade was welded at the top surface of the $12.7 \mathrm{~mm} \emptyset$ G.I. pipe just above the nozzle opening, and in a position that protrudes in front the nozzle. The nozzle was fabricated with a circular and rectangular opening having a $2 \mathrm{~mm}$ diameter and $1 \mathrm{~mm} \times 10 \mathrm{~mm}$ cross-section, respectively. 


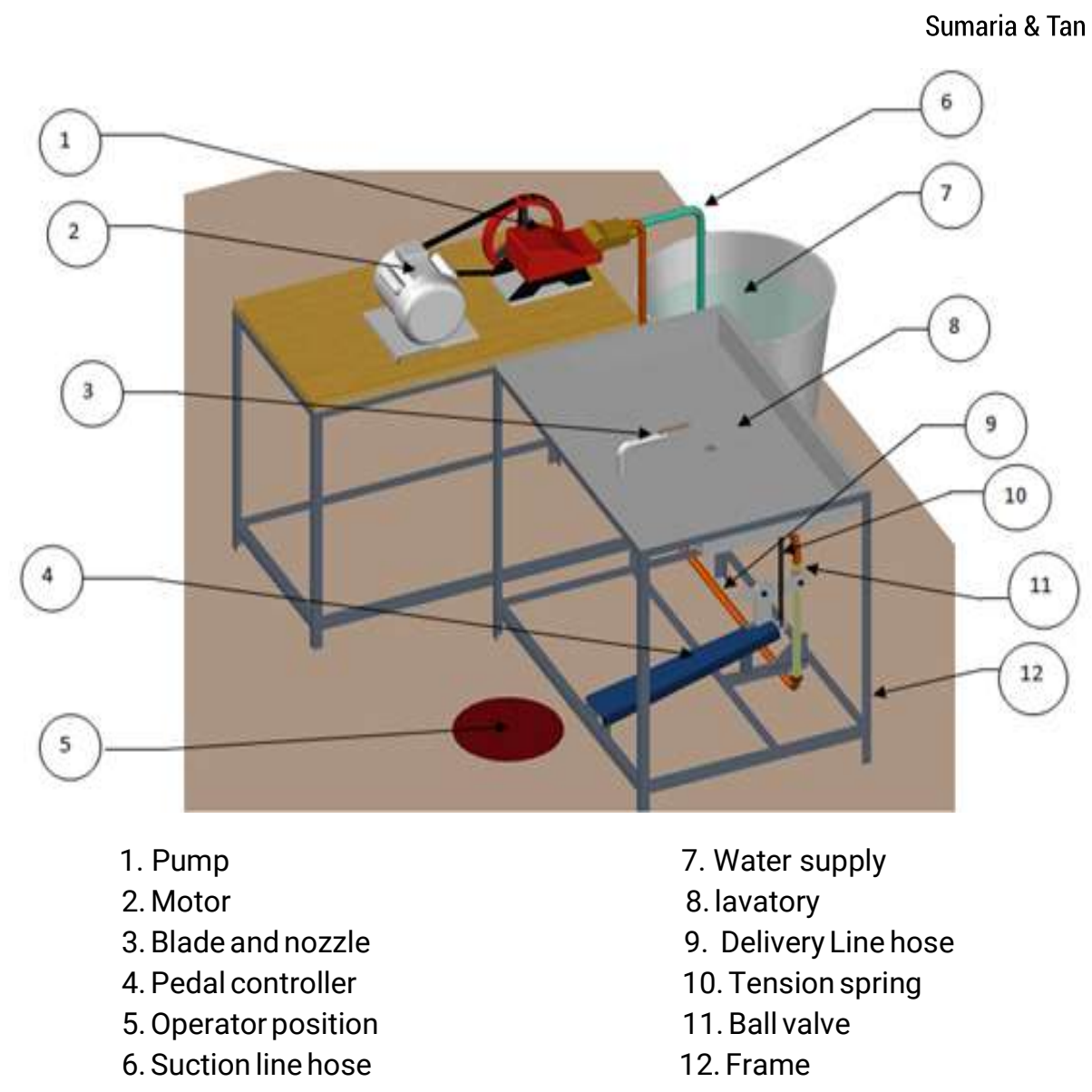

Figure 5 . The water jet-assisted cassava peeling machine showing the different parts

\section{Water Control and Delivery Assembly}

Potable water was used during the experiment and it was delivered through a $12.7 \mathrm{~mm}\left(1 / 2 \mathrm{in}\right.$.) flexible hose having a maximum allowable pressure of $65 \mathrm{~kg} / \mathrm{cm}^{2}$ capacity. The main controller of water was the ball valve, which has an inner diameter of $12.7 \mathrm{~mm}(1 / 2 \mathrm{in}$.). It was used to control the flow of water by means of a lever. The lever was bored $57 \mathrm{~mm} \times 10 \mathrm{~mm}$ on the other end parallel to the length and linked to the pedal in which the other end of the pedal was hinged. The pedal was mounted with a spring having a stiffness of $10 \mathrm{~N} / \mathrm{mm}$. The pedal was inclined $13^{\circ}$ with the horizontal.

\section{Frame and Table Assembly}

The main frame is made out of angle bars welded between joint and has frame dimension of $900 \mathrm{~mm}$ in length, $600 \mathrm{~mm}$ in width and $700 \mathrm{~mm}$ in height. The top of 
Development of waterjet-assisted cassava peeler

the frame has a stainless steel lavatory where the nozzle assembly was attached and where the cassava roots are placed during the peeling operation.

\section{Performance of the Peelers}

Table 1 presents the summary of the performance of the peelers in terms of the percent weight of peel, peeling efficiency, percent flesh tuber loss, and peeling capacity.

Table 1. Summary table of the performance of the peelers evaluated and the physical characteristics of the cassava roots used in the experiment

\begin{tabular}{|c|c|c|c|c|c|}
\hline \multirow[b]{2}{*}{ Parameter } & \multirow[b]{2}{*}{ Peeler Type } & \multicolumn{3}{|c|}{ Root Diameter Range } & \multirow[b]{2}{*}{ Mean } \\
\hline & & $\begin{array}{c}D_{1}= \\
35 \mathrm{~mm} \pm 5 \mathrm{~mm}\end{array}$ & $\begin{array}{c}D_{2}= \\
45 \mathrm{~mm} \pm 5 \mathrm{~mm}\end{array}$ & $\begin{array}{c}D_{3}= \\
55 \mathrm{~mm} \pm 5 \mathrm{~mm}\end{array}$ & \\
\hline \multicolumn{6}{|c|}{ Peeling capacity, kg/h } \\
\hline & Round Nozzle & 15.67 & 24.24 & 37.13 & 25.68 \\
\hline & Flat Nozzle & 12.66 & 20.12 & 32.27 & 21.68 \\
\hline & Manual & 11.12 & 16.67 & 25.44 & 17.74 \\
\hline & Mean & 13.15 & 20.34 & 31.61 & 21.70 \\
\hline \multicolumn{6}{|c|}{ Peeling Efficiency, \% } \\
\hline & Round Nozzle & 100 & 100 & 100 & 100 \\
\hline & Flat Nozzle & 100 & 100 & 100 & 100 \\
\hline & Manual & 100 & 100 & 100 & 100 \\
\hline & Mean & 100 & 100 & 100 & 100 \\
\hline \multicolumn{6}{|c|}{ Flesh tuber loss, $\%$} \\
\hline & Round Nozzle & nil & nil & nil & \\
\hline & Flat Nozzle & nil & nil & nil & \\
\hline & Manual & nil & nil & nil & \\
\hline & Mean & & & & \\
\hline Weight of peel & & 16.8 & 16.5 & 16.3 & 16.5 \\
\hline
\end{tabular}

\section{Peeling Output and Tuber loss}

During the peeling operation using the flat and circular nozzle openings, as shown in Figure 6, almost no losses of the flesh of the cassava tubers were observed, and it also shows a complete removal of peels, which means a $100 \%$ peeling efficiency for both nozzle types (Table 1). Furthermore, because of the water jet-assisted peeling, the peeled tubers were already washed clean.No soiled roots were found. 


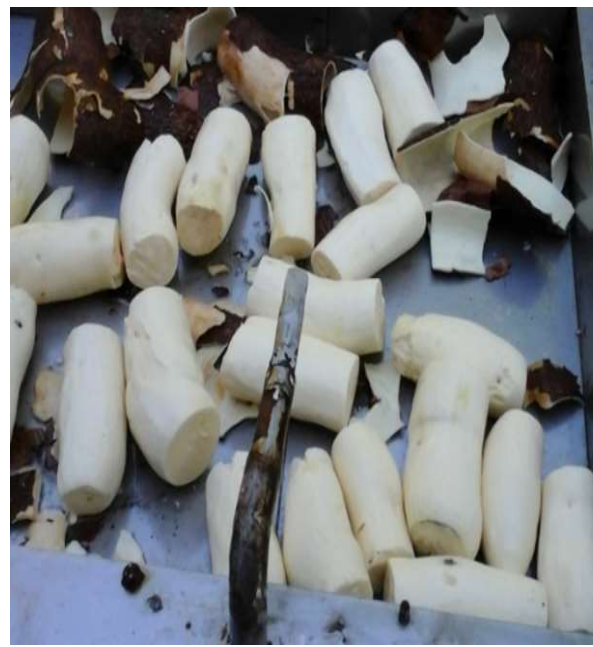

(a)

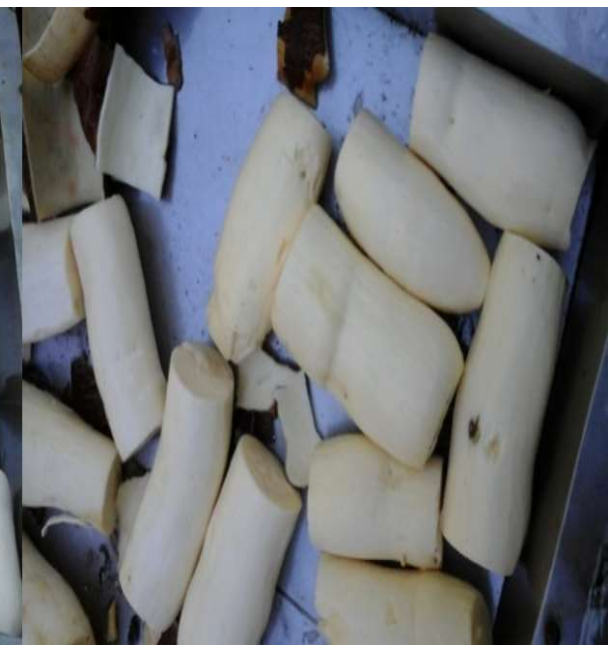

(b)

Figure 6. Peeled cassava after the peeling operation using the (a) circular nozzle opening and (b) flat nozzle opening water jet nozzles

\section{Peeling Capacity}

Analysis of variance of the peeling capacity in Table 2 shows that there was a significant difference using three different peelers at $5 \%$ level of significance, and with the diameter of cassava used in the experiment was significantly different at $1 \%$ level of significance.

Table 2. One-Way Analysis of Variance of the Peeling Capacity

\begin{tabular}{llllll}
\hline Source of Variation & $\begin{array}{l}\text { Sum of } \\
\text { Squares }\end{array}$ & $\mathrm{df}$ & $\begin{array}{l}\text { Mean } \\
\text { Square }\end{array}$ & F-value & p-value \\
\hline Peelers & 283.605233 & 2 & 141.802617 & $4.06^{*}$ & 0.0351 \\
Cassava diameter & 1559.099162 & 2 & 779.549581 & $22.30^{* \star}$ & $<0.0001$ \\
Experimental Error & 629.25206 & 18 & 34.958448 & & \\
Sampling Error & 41.665626 & 4 & 10.416407 & & \\
Total & 2513.622083 & 26 & & & \\
\hline
\end{tabular}

**significant at the $1 \%$ level *significant at the $5 \%$ level

Table 3 shows that the average peeling capacity in peeling three diameter ranges of cassava using the circular nozzle opening was not significantly higher than the flat nozzle opening but significantly higher than the manual peeling at $5 \%$ level of significance. There was no significant difference between the flat nozzle opening and manual peeling. The circular nozzle opening obtained the highest peeling capacity of $25.68 \mathrm{~kg} / \mathrm{h}$ because of the higher and concentrated water-jet 
Development of waterjet-assisted cassava peeler

volume than the flat nozzle opening but was only able to have a significant difference with manual peeling. Although there was no significant difference in capacity between the blade with flat nozzle and manual peeling, it is worthy to note that after the manual peeling operation, the peeled roots have still to go through a washing operation while the roots peeled through the water jet-assisted peeler with flat nozzle no longer need to be washed, thereby saving one processing operation. The economics of using the two systems though, have yet to be established.

Table 3. Tukey's Honest Significant Difference Test of the Peeling Capacity of the Different Nozzles including manual peeling using the knife

\begin{tabular}{ll}
\hline Treatments & Average Peeling Capacity $(\mathrm{kg} / \mathrm{h})$ \\
\hline Circular nozzle & $25.68 \mathrm{a}$ \\
Flat nozzle & $21.68 \mathrm{ab}$ \\
Manual peeling using knife & $17.74 \mathrm{~b}$ \\
\hline
\end{tabular}

*means with the same letter(s) are not significantly different at the $5 \%$ level

Figure 7 shows the trends of the peeling capacity of the cassava roots using different type of peelers. The figure reveals that the highest peeling capacity was attained using circular nozzle opening having an average peeling capacity of $37.12 \mathrm{~kg} / \mathrm{h}$, followed by the flat nozzle opening of $29.69 \mathrm{~kg} / \mathrm{h}$ and by manual of $24.3 \mathrm{~kg} / \mathrm{h}$ as the lowest peeling capacity having cassava root diameter ranges from $50 \mathrm{~mm}$ to $60 \mathrm{~mm}(55 \mathrm{~mm} \pm 5 \mathrm{~mm})$ of the three peelers.

It was observed that the peeling capacity of cassava roots decreased as the diameter of cassava decreases and the circular nozzle opening remains as the highest peeling capacity and the lowest peeling capacity using manual peeling of different diameter ranges of cassava roots.

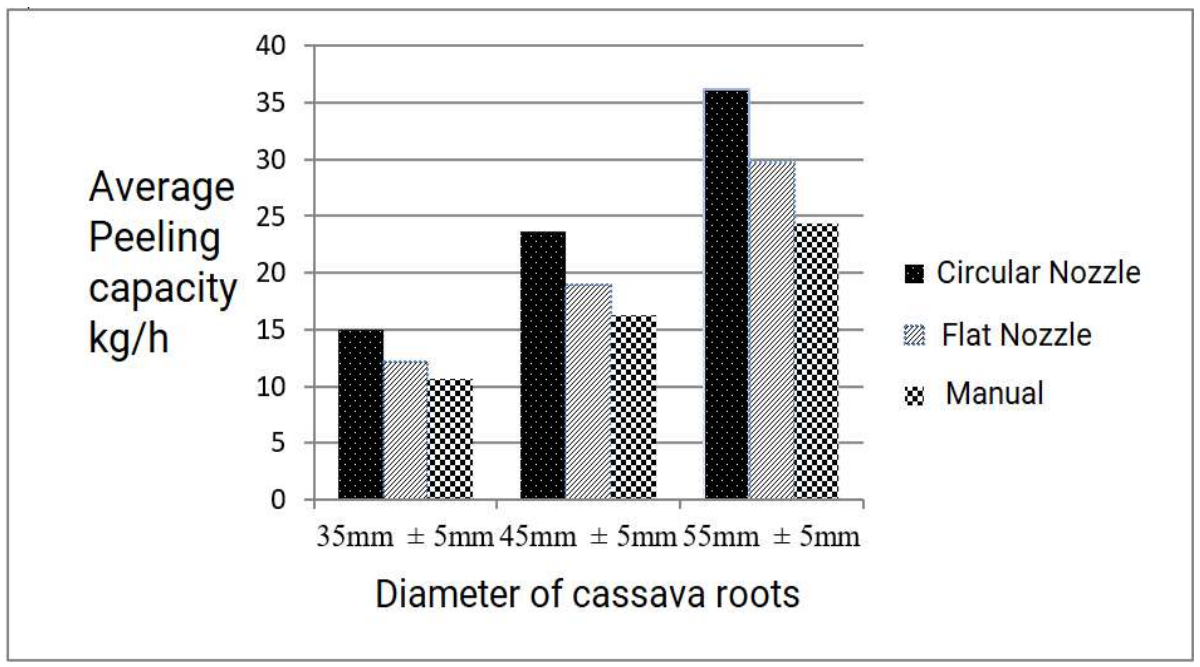

Figure 7. Average peeling capacity of cassava roots at three different types of peelers (blade with circular and flat nozzles, and manual peeler) at different root diameter of cassava 


\section{CONCLUSIONS AND RECOMMENDATIONS}

The water jet-assisted peeler with circular nozzle attained the highest peeling capacity compared to the water jet-assisted peeler with flat nozzle and to that of manual peeling. All the water jet-assisted peelers evaluated attained $100 \%$ high peeling efficiency and eliminated the washing operation of the peeled roots.

In terms of peeling capacity, the developed water jet-assisted cassava peeler with the circular nozzle opening had the highest peeling capacity of $37.12 \mathrm{~kg} / \mathrm{h}$ at a cassava tuber diameter range of $50 \mathrm{~mm}$ to $60 \mathrm{~mm}$.

For further evaluation is to conduct experiments that would determine the effect of different water pressure to the two types of nozzles to the peeling capacity and efficiency in the water jet-assisted peeling of cassava roots. Furthermore, a manual control water jet-assisted peeler instead of the pedal control needs to be evaluated.

\section{REFERENCES}

Adetan DA, Adekoya LO \& Aluko OB. 2003,"Characterisation of some properties of cassava root tubers". Journal of Food Engineering, 59:349-353

Food and Agricultural Organisation. 1991. Production Yearbook for 1990.Food and Agricultural Organisation of the United Nations, Rome, Italy

Hassan AB. 2012. Design and Fabrication of a Cassava Peeling Machine. Journal of Engineering, 2:01-08

Hillocks RJ. 2002. Cassava in Africa. In Cassava: Biology, Production and Utilization. Eds. CAB International, Wallingford

IITA. 1997. Cassava in Africa: past, present and future. International Institute of Tropical Agriculture, Ibadan Nigeria

Kawano K. 2000. Cassava as a Source of Animal Feed and Income Generation in Upland Farming Communities of Asia. Science Report of the Faculty of Agriculture, Kobe University, Japan, 24(1):123-124

Onwueme IC. 1978. The Tropical Tuber Crops: Yam, Cassava, Sweet potato and Cocoyam, Chichester: John Wiley and Sons 